\title{
PENGARUH VARIASI Electrical Conductivity (EC) LARUTAN NUTRISI HIDROPONIK RAKIT APUNG PADA FASE VEGETATIF CEPAT TERHADAP PERTUMBUHAN DAN HASIL TANAMAN SAWI PAKCOY (Brassica Rapa L.)
}

\author{
Evita Eda Efendi ${ }^{1}$, Djoko Murdono ${ }^{2}$ \\ ${ }^{1}$ Agroteknologi, Fakultas Pertanian dan Bisnis, Universitas Kristen Satya Wacana, \\ Indonesia. \\ ${ }^{2}$ Dosen Fakultas Pertanian dan Bisnis, Universitas Kristen Satya Wacana, Indonesia. \\ E-Mail: evita.edaefendi25@gmail.com
}

\begin{abstract}
ABSTRAK
Pengaruh Variasi Electrical Conductivity (EC) Larutan Nutrisi Hidroponik Rakit Apung Pada Fase Vegetatif Cepat Terhadap Pertumbuhan Dan Hasil Tanaman Sawi Pakcoy (Brassica Rapa L.) Sawi pakcoy merupakan salah satu jenis sayuran mudah dibudidayakan, pakcoy juga banyak dijadikan sebagai peluang bisnis karena peminatnya yang cukup banyak. HIdroponik rakit apung merupakan salah satu teknik budidaya tanaman tanpa media tanah melainkan dengan media air. Keberhasilan budidaya tanaman secara hidroponik dipengaruhi oleh pengontrolan Electrical Conductivity (EC) didalam air. Penelitian ini bertujuan menetukan pengaruh dan nilai variasi EC yang mampu memberikan pertumbuhan dan hasil yang terbaik pada tanaman sawi pakcoy yang ditanam secara hidroponik rakit apung. Penelitian menggunakan Rancangan Acak Kelompok (RAK) terdiri dari 5 perlakuan. Masing-masing perlakuan diulang sebanyak 5 kali. Penelitian menunjukkan adanya pengaruh variasi EC larutan hidroponik terhadap pertumbuhan dan hasi tanaman sawi pakcoy pada beberapa parameter pengamatan. Pengaruh perlakuan yang signifikan terdapat pada parameter tinggi tananam, jumlah daun, luas daun, dan berat segar tanaman. Sedangkan total klorofil dan berat kering tanaman tidak menunjukkan adanya beda nyata antar perlakuan. Perlakaun D ((EC 1,6 mS/cm (7-14HSS) dan $2,4 \mathrm{mS} / \mathrm{cm}$ (15-41HSS)) mampu memberikan pertumbuhan dan hasil yang terbaik pada tanaman sawi pakcoy. Perlakuan D memberikan hasil yang berpengaruh nyata pada parameter pengamatan seperti tinggi tanaman, jumlah daun, luas daun, dan berat basah tanaman.
\end{abstract}

Kata Kunci : Electical Conductivity (EC), Hidroponik, Sawi Pakcoy.

\begin{abstract}
The Effect of Variations in Electrical Conductivity (EC) of Floating Raft Hydroponic Nutrient Solutions in the Fast Vegetative Phase on the Growth and Yield of Mustard Pakcoy (Brassica Rapa L.) The mustard pakcoy is one type of the vegetable that is easy to cultivate. Moreover, pakcoy is widely used as a business opportunity since it has many enthusiasts. Floating raft hydroponics is a plant cultivation technique without soil media but with water media. The success of hydroponic cultivation is influenced by controlling the Electrical Conductivity $(E C)$ in the water. This research aims to determine the effect and the value of EC variations that are able to provide the best growth and yields to pakcoy mustard plants grown hydroponically on floating rafts. The study used a "Rancangan Acak Kelompok" (RAK) consisting of 5 treatments. Each treatment was repeated 5 times. The research showed that there was an effect of EC variations in hydroponic solutions on the growth of pakcoy mustard plants on several observation parameters. The significant effect of treatment was found in the parameters of plant height, a number of leaves, leaf area, and fresh plant weight. Meanwhile, the total chlorophyll and dry weight of plants did not show any significant difference between the treatments. Treatment D ((EC $1.6 \mathrm{mS} / \mathrm{cm}$ (7-14HSS) and 2.4 $\mathrm{mS} / \mathrm{cm}(15-41 \mathrm{HSS}))$ ) was able to provide the best growth and yield of mustard pakcoy. Treatment of $D$ gave results that are significantly affected by the observed parameters. Such as, plant height, number of leaves, leaf area, and plant wet weight.
\end{abstract}

Key words : Electical Conductivity (EC), Hydroponics, Mustard pakcoy. 


\section{PENDAHULUAN}

Sawi pakcoy (Brassica rapa L.) merupakan salah satu jenis sayuran yang mudah untuk dibudidayakan. Sawi pakcoy tidak tergantung pada musim sehingga dapat dipanen sepanjang tahun. Masa panen pun terbilang cukup pendek, karena sudah dapat dipanen setelah 40 hari ditanam. Selain mudah dibudidayakan, pakcoy juga banyak dijadikan sebagai peluang bisnis karena peminatnya yang cukup banyak. Permintaan pasarnya juga cukup stabil, sehingga resiko kerugian sangat kecil (Wibowo \& Asriyanti, 2013).

Salah satu teknik budidaya yang dapat digunakan untuk budidaya tanaman sawi pakcoy yaitu hidroponik. Hidroponik merupakan salah satu teknik budidaya yang tidak menggunakan media tanah, melainkan menggunakan media air dengan penambahan larutan nutrisi pada medianya. Budidaya secara hidroponik dapat dilaksanakan diberbagai tempat dan sepanjang tahun tanpa mengenal musim (Asmana, Abdullah, \& Dwi Putra, 2017). Pemeliharaan tanaman hidroponik cukup mudah karena tempat budidaya relatif bersih, tanaman tidak terkena air hujan, serangan hama dan penyakit relatif kecil, serta tanaman yang lebih sehat dengan produktivitas yang tinggi (Hartus, T., 2010).

Salah satu faktor yang sangat berpengaruh pada keberhasilan budidaya tanaman secara hidroponik yaitu kepekatan larutan nutrisi. Menurut Adimihardja, Setyono, \& Nurkhotimah (2011), Pengontrolan Electrical Conductivity (EC) didalam air merupakan kunci utama pemberian larutan nutrisi pada sistem hidroponik. Pengaturan nilai EC selain dapat meningkatkan pertumbuhan tanaman juga dapat menghemat penggunaan nutrisi hidroponik. Pemberian EC larutan nutrisi hidroponik pada vegetatif I sangat berpengaruh terhadap tinggi, jumlah daun, luas daun, diameter bonggol, panjang akar, bobot segar, dan bobot kering tanaman sawi. Perlakuan EC 2,4 $\mathrm{mS} / \mathrm{cm}$ menunjukkan hasil yang tidak berbeda nyata dengan EC 1,6 mS/cm dan 2,0 $\mathrm{mS} / \mathrm{cm}$ (Ifanto \& Suprihati, 2019). Berdasarkan penelitian Frasetya dkk. (2018), didapatkan hasil pada tanaman selada dengan aplikasi EC Vegetatif I (114HSS) $1,6 \mathrm{mS} / \mathrm{cm}$ sudah memberikan pengaruh terhadap parameter tinggi tanaman. Aplikasi EC pada vegetatif II (15-25HSS) 2,4 $\mathrm{mS} / \mathrm{cm}$ menghasilkan luas daun selada dan berat segar tanaman tertinggi. Efisiensi pemberian unsur hara dicapai pada EC $2,4 \mathrm{mS} / \mathrm{cm}$. Pemberian EC lebih dari $2,6 \mathrm{mS} / \mathrm{cm}$ pada parameter luas daun menghasilkan luas daun lebih sempit.

Berdasarkan data tersebut maka dalam penelitian ini akan dicoba menggunakan EC yang ideal yaitu 1,6 $\mathrm{mS} / \mathrm{cm}$ untuk efisiensi penggunaan nutrisi pada vegetatif I, sedangkan EC ideal pada vegetatif II belum ditemukan. Oleh karena itu pada penelitian ini akan fokus untuk menemukan EC ideal pada vegetatif II dengan menggunakan kombinasi EC pada vegetatif I (714HSS) dengan EC $1,6 \mathrm{mS} / \mathrm{cm}$ dan variasi EC pada vegetatif II (15-41HSS) dengan EC $1,8 \mathrm{mS} / \mathrm{cm}, 2,0 \mathrm{mS} / \mathrm{cm}, 2,2$ $\mathrm{mS} / \mathrm{cm}, 2,4 \mathrm{mS} / \mathrm{cm}$, dan $2,6 \mathrm{mS} / \mathrm{cm}$. Penelitian ini bertujuan menetukan pengaruh dan nilai variasi EC yang mampu memberikan pertumbuhan dan hasil yang terbaik pada tanaman sawi pakcoy yang ditanam secara hidroponik rakit apung.

\section{METODE PENELITIAN}

\subsection{Tempat dan Waktu}

Penelitian dilaksanakan pada Mei 2021 s.d. Agustus 2021. Penelitian dilaksanakan di Kebun Percobaan Kartini, Fakultas Pertanian dan 
Bisnis Universitas Kristen Satya Wacana, Tepatnya di jalan Kartini No. 11 dan Laboratorium Gedung C Fakultas Pertanian dan Bisnis Universitas Kristen Satya Wacana.

\subsection{Bahan dan Alat}

Bahan yang diunakan dalam penelitian yaitu benih sawi Takii Seed, Pupuk AB mix produksi CV. Agrifam., dan air. Alat yang digunakan dalap penelitian ini yaitu EC meter, styrofoam, bak penampung nutrisi, label, alat tulis, aerator, rockwool, penggaris, $\mathrm{pH}$ meter, klorofil meter SPAD, gelas ukur $1000 \mathrm{ml}$, gelas ukur $250 \mathrm{ml}$, ember, plastik, timbangan analitik, kabel rol, dan netpot.

\subsection{Rancangan Penelitian}

Penelitian menggunakan Rancangan Acak Kelompok (RAK) terdiri dari 5 perlakuan $\quad(\mathrm{A}=\mathrm{EC} \quad(\mathrm{VI}=1,6 \mathrm{mS} / \mathrm{cm}$, $\mathrm{VII}=1,8 \mathrm{mS} / \mathrm{cm}) ; \mathrm{B}=\mathrm{EC}(\mathrm{V} 1=1,6 \mathrm{mS} / \mathrm{c}$ $\mathrm{m}, \mathrm{VII}=2,0 \mathrm{mS} / \mathrm{cm} ; \mathrm{C}=\mathrm{EC}(\mathrm{VI}=1,6$ $\mathrm{mS} / \mathrm{cm}, \quad \mathrm{VII}=2,2 \mathrm{mS} / \mathrm{cm} ; \quad \mathrm{D}=\mathrm{EC}$ (VI=1,6 $\mathrm{mS} / \mathrm{cm} ; \quad \mathrm{VII}=2,4 \mathrm{mS} / \mathrm{cm}$; $\mathrm{E}=\mathrm{EC} 1,6 \mathrm{mS} / \mathrm{cm}, \mathrm{VII}=2,6 \mathrm{mS} / \mathrm{cm})$ ). Masing-masing perlakuan diulang sebanyak 5 kali. Aplikasi EC larutan nutrisi hidroponik pada perlakuan Vegetatif I (lambat) diberikan pada saat tanaman berumur 7-14 HSS dengan EC 1,6 $\mathrm{mS} / \mathrm{cm}$ dan aplikasi variasi EC larutan nutrisi hidroponik pada setiap perlakuan Vegetatif II (cepat) diberikan pada saat tanaman berumur 15-41 HSS.

\subsection{Prosedur Pelaksanaan Peneliitian}

a. Persiapan instalasi hidroponik rakit apung

Bak nutrisi yang digunakan berukuran $37,5 \mathrm{~cm} \times 30 \mathrm{~cm}$ x $12 \mathrm{~cm}$. Bak nutrisi ditutup menggunakan Styrofoam dengan ketebalan $3 \mathrm{~cm}$ dengan 4 lubang tanam dan jarak antar lubang $7,5 \mathrm{~cm}$.

b. Persemaian bibit sawi pakcoy

Benih yang digunakan ialah Benih Sawi Takii seed. Benih yang akan digunakan diseleksi dengan merendam benih ke dalam air, benih yang baik akan tenggelam. Penanaman dilakukan dengan memasukkan masing-masing benih kedalam rockwool selama 7 hari.

c. Penanaman

Pada saat tanaman berumur 7HSS rockwool dimasukkan kedalam netpot dan dipindahkan kedalam lubang styrofoam pada bak yang berisi larutan nutrisi hidroponik dengan EC $1,6 \mathrm{mS} / \mathrm{cm}$. Pada saat tanaman berumur 15 HSS, selanjutnya dilakukan pengelompokan tanaman dengan pertumbuhan yang seragam dan perlakuan EC yang bervariasi. EC larutan nutrisi hidroponik dinaikkan dengan EC yang bervariasi sesuai perlakuan, yakni perlakuan A $(\mathrm{VII}=1,8 \mathrm{mS} / \mathrm{cm}), \quad$ B $\quad(\mathrm{VII}=2,0$ $\mathrm{mS} / \mathrm{cm}), \quad \mathrm{C} \quad(\mathrm{VII}=2,2 \mathrm{mS} / \mathrm{cm}), \quad \mathrm{D}$ $(\mathrm{VII}=2,4 \quad \mathrm{mS} / \mathrm{cm}), \quad \mathrm{E} \quad(\mathrm{VII}=2,6$ $\mathrm{mS} / \mathrm{cm})$.

d. Pemeliharaan Tanaman

Pemeliharaan dilakukan dengan pengendalian hama penyakit bila diperlukan yakni terlihat adanya gejala serangan hama atau penyakit dan pengontrolan EC yang digunakan.

e. Panen

Pemanenan dilakukan pada hari ke 41 HSS dengan mencabut tanaman dari netpot dan melepaskan rockwool beserta akar tanaman sawi selanjutnya tanaman sawi ditimbang dan dihitung bobotnya.

\subsection{Pengamatan}

Pengamatan yang diamati di dalam penelitian ini dibagi menjadi 2 
yaitu pengamatan utama dan pengamatan selintas. Pengamatan utama meliputi tinggi tanaman, jumlah daun, berat brangkasan basah, berat brangkasan kering. Pengamatan selintas meliputi kondisi larutan ( $\mathrm{pH}$ dan EC), kondisi udara (suhu dan kelembaban), dan klorofil.

\subsection{Analisis Data}

Data analisis dengan metode analisis varian (ANOVA). Perlakuan yang memiliki pengaruh signifikan kemudian dilanjutkan dengan menggunakan uji Duncan's Multiple Range Test (DMRT) pada taraf nyata $5 \%$. Analisis dilakukan menggunakan aplikasi Exel dan SPSS.

\section{HASIL PENELITIAN DAN PEMBAHASAN}

\subsection{Kondisi Udara (Suhu dan Kelembaban) dan pH Larutan Nutrisi}

Kondisi udara yang diamati selama penelitian yaitu suhu dan kelembaban menggunakan alat hygrometer Htc- 2 . Pengamatan suhu dan kelembaban dilakukan setiap hari. Rata-rata suhu udara selama penelitian yaitu $31{ }^{\circ} \mathrm{C}$ dengan kelembaban $56 \%$. Suhu yang ada pada tempat penelitian tergolong ideal untuk budidaya tanaman sawi pakcoy, sedangkan kelembaban masih kurang ideal untuk pertumbuhan tanaman sawi. Menurut Rukmana (2002), Suhu yang diperlukan untuk tanaman sawi yaitu $27{ }^{\circ} \mathrm{C}$ sampai $32{ }^{\circ} \mathrm{C}$, sedangkan kelembaban yang sesuai untuk pertumbuhan sawi yaitu berkisar antara 80-90\%.

Penyerapan nutrisi pada budidaya tanaman secara hidroponik dipengaruhi oleh pH larutan. Menurut Yama dan Kartiko (2019), dalam budidaya tanaman sawi secara hidroponik $\mathrm{pH}$ yang dianjurkan yaitu 5,5 - 6,5. Apabila larutan nutrisi memiliki nilai $\mathrm{pH}$ dibawah 5,5 atau lebih dari 6,5 akan menyebabkan beberapa unsur hara yang mengendap sehingga tidak dapat diserap oleh tanaman. Rata-rata keasaman selama budidaya tanaman yaitu perlakuan A dengan keasaman yaitu 6,5, perlakuan B dengan keasaman 6,4 , prlakuan $\mathrm{C}$ dengan keasaman 6,3, sedangkan perlakuan D dan E memiliki rata-rata keasaman yang sama yaitu 6,2. Nilai $\mathrm{pH}$ pada larutan dengan perlakuan EC yang lebih rendah (A, B, dan C) memiliki rata-rata yang lebih tinggi dibanding dengan nilai perlakuan EC yang tinggi (D dan E). Hal ini sesuai dengan pendapat Yama dan Kartiko (2019), pH pada suatu larutan nutrisi akan menurun seiring dengan meningkatnya konsentrasi larutan nutrisi.

Berdasarkan uji DMRT taraf 5\% didaptkan hasil bahwa pertumbuhan dan hasil tanaman sawi pakcoy dengan perlakuan variasi EC berpengaruh nyata pada parameter tinggi tanaman luas daun, dan berat basah namun tidak berpengaruh nyata terhadap jumlah daun, klorofil, dan berat kering tanaman sawi pakcoy. Berdasarkan data pada Tabel 1. Dapat dilihat bahwa dari semua parameter pengamatan, perlakuan variasi EC yang nyata memberikan hasil yang terbaik dari semua perlakuan yaitu perlakuan D (EC (VI=1,6 $\mathrm{mS} / \mathrm{cm}$; $\mathrm{VII}=2,4 \mathrm{mS} / \mathrm{cm})$ )

\subsection{Tinggi Tanaman}

Analisis tinggi tanaman pada umur 17HSS hingga $23 \mathrm{HSS}$, perlakuan variasi EC tidak berpengaruh nyata pada tinggi tanaman sawi pakcoy. Hal tersebut bisa disebabkan karena unsur hara pada setiap perlakuan masih cukup untuk memenuhi pertumbuhan tanaman sawi pakcoy. Sedangkan pada umur 26 HSS hingga 41 HSS perlakuan variasi EC berpengaruh nyata terhadap tinggi tanaman sawi 
pakcoy. Perlakuan variasi EC sudah sesuai dengan kebutuhan tanaman sehingga adanya perbedaan pada tinggi tanaman antar perlakuan. Kebutuhan unsur hara akan semakin meningkat seiring dengan bertambahanya umur tanaman. Menurut Anggraini (2017), setiap fase pertumbuhan pada tanaman memerlukan EC yang berbeda. Pada saat tanaman masih kecil maka EC yang dibutuhkan juga sedikit. Umur tanaman yang semakain meningkat maka EC yang dibutuhkan juga akan semakin meningkat.

Variasi tinggi tanaman pada tabel 1 . Memberikan informasi bahwa perlakuan dengan variasi EC berpengaruh pada parameter tinggi tanaman. Perlakuan D $(\mathrm{VI}=\mathrm{EC} 1,6 \mathrm{mS} / \mathrm{cm} ; \mathrm{VII}=\mathrm{EC} 2,4$ $\mathrm{mS} / \mathrm{cm}$ ) menghasilkan rata-rata tinggi tanaman yang tertinggi pada semua umur tanaman. Sedangkan perlakuan E dengan nilai EC tertinggi cenderung menghasilkan tinggi tanaman yang relatif sama dengan perlakuan EC yang lebih rendah yaitu A dan B. Hal ini bisa (perlakuan E). Menurut Pratiwi, Subandi, \& Mustari (2015), kepekatan larutan yang dibutuhkan untuk pertumbuhan tanaman sawi yaitu EC 1,5-2,0 $\mathrm{mS} / \mathrm{cm}$, dengan nilai toleran yaitu EC $2,5 \mathrm{mS} / \mathrm{cm}$. Menurut Wijayani \& Widodo (2005), kepekatan larutan nutrisi yang tinggi dapat berpengaruh pada tidak maksimumnya serapan hara oleh akar tanaman. Terjadinya hal tersebut karena tekanan osmose sel menjadi lebih kecil dibandingkan tekanan osmose sel diluar sehingga justru akan terjadi aliran balik cairan sel-sel tanaman (plasmolisis).

\subsection{Jumlah Daun}

Hasil analisis pada Tabel 1. Jumlah daun tidak berpengaruh nyata pada umur 41HSS. Namun perlakuan D (Vegetatif I $=\mathrm{EC} 1,6 \mathrm{mS} / \mathrm{cm}$; Vegetatif $\mathrm{II}=\mathrm{EC} 2,4$ $\mathrm{mS} / \mathrm{cm})$ menghasilkan rata-rata jumlah daun yang tertinggi dari perlakuan lainnya. Menurut Rizal (2017), penambahan jumlah daun pada tanaman berkaitan dengan tinggi tanaman. Tinggi tanaman yang semakin meningkat akan

Tabel 1. Rekapitulasi Data Rata-rata Pertumbuhan Tanaman Umur 41 HSS

\begin{tabular}{|c|c|c|c|}
\hline Perlakuan & Tinggi Tanaman $(\mathrm{cm})$ & Jumlah Daun (Helai) & Luas Daun $(\mathrm{Cm} 2)$ \\
\hline $\mathrm{A}$ & $28,27 \mathrm{a}$ & 11,95 & $144.422 \mathrm{a}$ \\
\hline B & $28,78 \mathrm{ab}$ & 12,35 & $140.638 \mathrm{a}$ \\
\hline $\mathrm{C}$ & $29,63 b$ & 12,85 & $157.875 \mathrm{a}$ \\
\hline $\mathrm{D}$ & $30,93 \mathrm{c}$ & 13,15 & $195.445 b$ \\
\hline $\mathrm{E}$ & $28,63 \mathrm{ab}$ & 11,85 & $153.167 \mathrm{a}$ \\
\hline Uji F Taraf 5\% & $*$ & ns & $*$ \\
\hline
\end{tabular}

Keterangan: $\left(^{*}\right)$ berpengaruh nyata pada taraf uji 5\%; (tn) tidak berpengaruh nyata pada taraf uji 5\%; Angka-angka dengan huruf yang sama pada kolom yang sama berarti tidak berbeda nyata berdasarkan uji DMRT pada taraf $5 \%$

disebabkan. Hal ini bisa disebabkan karena adanya hambatan penyerapan nutrisi yang tidak maksimal oleh tanaman pada perlakuan tersebut menghasilkan ruas batang tanaman yang semakin banyak, sehingga daun yang tumbuh pada ruas batang juga akan semakin meningkat. Menurut Priyanggi, 
Nugroho, \& Sari (2019), Pertambahan jumlah daun yang tinggi dapat disebabkan karena penyerapan unsur nitrogen yang tinggi pula. AB Mix mengandung unsur hara makro $\mathrm{N}$ sebesar $24,61 \%$, $\mathrm{P} 4,71 \%$, dan nilai $\mathrm{K}$ sebesar $39,10 \%$. Menurut Tripama \& Yahya berpengaruh pada bertambahnya jumlah daun sehingga daun semakin berkembang dan bertambah ukuran (Suseno dan Widyawati, 2020). Analisis ragam pada luas daun tanaman sawi pakcoy menunjukkan bahwa perlakuan variasi EC berpengaruh terhadap luas

Tabel 2. Rekapitulasi Data Rata-rata Hasil Tanaman

\begin{tabular}{cccc}
\hline Perlakuan & Klorofil $(\mu \mathrm{g} / \mathrm{m})$ & Berat Basah $(\mathrm{gr})$ & Berat Kering $(\mathrm{gr})$ \\
\hline A & 37.50 & $72.22 \mathrm{a}$ & 3.49 \\
B & 37.72 & $74.45 \mathrm{a}$ & 3.45 \\
C & 36.24 & $76.05 \mathrm{a}$ & 3.46 \\
D & 38.06 & $99.33 \mathrm{~b}$ & 4.20 \\
E & 36.26 & $68.47 \mathrm{a}$ & 3.11 \\
\hline Uji F Taraf 5\% & $\mathrm{ns}$ & $*$ & $\mathrm{~ns}$ \\
\hline
\end{tabular}

Keterangan: (*) berpengaruh nyata pada taraf uji 5\%; (tn) tidak berpengaruh nyata pada taraf uji 5\%; Angka-angka dengan huruf yang sama pada kolom yang sama berarti tidak berbeda nyata berdasarkan uji DMRT pada taraf $5 \%$

(2018) Proses pembentukan organ daun pada tanaman dibutuhkan unsur nitrogen dalam jumlah yang banyak.

Semakin tinggi kepekatan larutan nutrisi yang digunakan maka semakin tinggi pula jumlah daun yang dihasilkan oleh tanaman. Namun hal ini tidak berlaku pada perlakuan E (EC tertinggi) yang menghasilkan rata-rata jumlah daun tanaman sawi pakcoy terendah dari semua perlakuan. Hal ini bisa disebabkan menurunnya serapan hara oleh akar tanaman akibat kepekatan larutan nutrisi yang tinggi. Menurut Sukawati (2010), efisiensi penyerapan unsur hara oleh akar tanaman menurun akibat nilai EC larutan nutrisi yang terlalu tinggi. Berkurangnya jumlah hara yang diserap oleh akar tanaman akan berpengaruh pada terhambatnya proses fotosintesis. Hal tersebut akan menyebabkan energi yang dibutuhkan untuk proses pembentukan organ-organ tanaman seperti daun akan terhambat.

\subsection{Luas Daun}

Kebutuhan unsur hara yang tercukupi pada suatu tanaman akan daun tanaman (Tabel 1). Perlakuan D (Vegetatif II = EC EC $2,4 \mathrm{mS} / \mathrm{cm}$ ) menghasilkan luas daun yang berbeda nyata dengan perlakuan lainnya. Hal ini sejalan dengan penelitian Frasetya, Taofik, \& Firdaus (2018), variasi EC tanaman selada pada perlakuan $\mathrm{C}$ (vegetatif $\mathrm{II}=\mathrm{EC} 2,4 \mathrm{mS} / \mathrm{cm}$ ) memiliki luas daun yang lebih optimum dari semua perlakuan A (vegetatif II = EC 2,0 $\mathrm{mS} / \mathrm{cm}$ ); $\mathrm{B}$ (vegetatif $\mathrm{II}=\mathrm{EC}=2,2$ $\mathrm{mS} / \mathrm{cm}$ ); dan $\mathrm{D}$ (vegetatif $\mathrm{II}=2,6$ $\mathrm{mS} / \mathrm{cm})$.

untuk sintesis klorofil sudah tercukupi pada semua perlakuan. Menurut Santoso \& Widyawati (2020), ketersediaan unsur hara untuk sintesis klorofil yang sudah tercukupi menyebabkan tidak adanya perbedaan yang nyata semua perlakuan pada parameter total klorofil tanaman sawi pakcoy. Hara N, P, K, Mg dan S merupakan unsur pembentukan klorofil.

\subsection{Berat Basah dan Berat Kering}

Hasil dari budidaya tanaman sawi dapat dilihat dari pertumbuhannya, dimana semakin baik pertumbuhan tanaman sawi pakcoy maka akan 
semakin baik pula hasilnya. Berat basah dan berat kering tanaman merupakan parameter yang dapat digunakan untuk mengetahui hasil dari proses dan pertumbuhan tanaman sawi pakcoy. Parameter berat basah dapat digunakan untuk mengetahui seberapa besar

\subsection{Klorofil}

Hasil analisis sidik ragam menunjukkan semua perlakuan variasi EC tidak berpengaruh terhadap klorofil daun tanaman sawi pakcoy. Menurut Yama dan Kartiko (2019), kandungan klorofil pada suatu tanaman tidak bergantung pada konduktivitas dan tekanan osmotik yang tinggi, sedangkan konduktivitas dan tekanan osmotik yang tinggi karena adanya nutrisi dengan konsentrasi yang tinggi. Kandungan klorofil pada semua perlakuan terlihat memberikan pengaruh yang sama terhadap nilai klorofil daun. Hasil ini diduga krena unsur hara yang diperlukan serapan unsur hara dan air pada pertumbuhan tanaman sawi pakcoy. Sedangkan berat kering merupakan hasil bersih akumulasi senyawa organik yang berhasil disintesis tanaman (Buntoro, Rogomulyo, \& Trisnowati, 2014).

Berdasarkan data pada tabel 2. perlakuan D merupakan perlakuan yang menghasilkan berat segar yang nyata lebih berat dibanding perlakuan lainnya, sedangkan perlakuan A, B, C, dan E menghasilkan berat segar yang tidak berbeda nyata dan cenderung menghasilkan berat segar tanaman yang sama. Hal ini sejalan dengan penelitian Hidayanti \& Kartika (2019), perbedaan berat basah pada tanaman bayam dipengaruhi oleh pemberian dosis laurutan nutrisi yang berbeda. Pemberian nutrisi AB Mix yang sesuai dengan kebutuhan tanaman akan mendukung pertumbuhan tanaman dengan hasil yang optimal (Rizal, 2017).
Hasil tanaman dipengaruhi oleh beberapa faktor pertumbuhan seperti tinggi tanaman, jumlah daun, dan luas daun. Semakin baik pertumbuhan suatu tanaman, maka semakin meningkat pula hasil berat segar tanaman (Suseno dan Widyawati, 2020). Hal ini sesuai dengan hasil yang didapatkan dimana perlakuan D menghasilkan tinggi tanaman, jumlah daun, dan luas daun yang tertinggi dari semua perlakuan. Menurut Sarido \& Junia (2017), jumlah daun berpengaruh juga pada berat segar tanaman sawi. Semakin banyak jumlah daun maka berat segar yang dihasilkan juga akan semakin meningkat, karena daun merupakan zink bagi tanaman. Daun merupakan organ tanaman sayuran yang banyak mengandung air, sehingga jumlah daun yang semakin tinggi maka kadar air pada suatu tanaman juga akan semakin tinggi yang akan menyebabkan berat segar tanaman akan tinggi pula.

Rata-rata berat kering pada tabel 2 . Perlakuan D menghasilkan berat kering tertinggi dibanding perlakuan lainnya, sedangkan perlakuan $\mathrm{E}$ menghasilkan rata-rata berat kering terendah dari semua perlakuan. Hal ini menunjukkan bahwa perlakuan D menghasilkan pertumbuhan tanaman dengan aktifitas metabolisme yang berlangsung lebih baik dibanding perlakuan lainnya.

Aktifitas metabolisme tanaman seperti fotosintesis yang lebih baik atau efisien ditandai dengan hasil dari bobot kering tanaman sawi pakcoy. Hal ini sejalan dengan pendapat Sarif, Hadid, \& Wahyudi (2015), berat kering merupakan hasil bersih fotosintesis yang diendapkan setelah kadar airnya dikeringkan. Hasil berat kering tanaman merupakan petunjuk dari keberhasilan pertumbuhan tanaman. Peningkatan berat kering tanaman berkaitan dengan metabolisme tanaman atau kondisi pertumbuhan tanaman yang lebih baik bagi berlangsungnya aktifitas metabolisme 
tanaman seperti fotosintesis. Oleh karena itu, berat kering yang semakin besar menunjukkan proses fotosintesis yang berlangsung lebih efisien dan produktifitas serta perkembangan sel-sel jaringan semakin tinggi dan cepat, sehingga pertumbuhan tanaman juga akan lebih baik.

\section{KESIMPULAN}

Penelitian menunjukkan adanya pengaruh variasi EC larutan hidroponik terhadap pertumbuhan dan hasi tanaman sawi pakcoy pada beberapa parameter pengamatan. Pengaruh perlakuan yang signifikan terdapat pada parameter tinggi tananam, jumlah daun, luas daun, dan berat segar tanaman. Sedangkan total klorofil dan berat kering tanaman tidak menunjukkan adanya beda nyata antar perlakuan.

Perlakaun D ((EC $1,6 \mathrm{mS} / \mathrm{cm}$ (714HSS) dan 2,4 $\mathrm{mS} / \mathrm{cm}$ (15-41HSS)) mampu memberikan pertumbuhan dan hasil yang terbaik pada tanaman sawi pakcoy. Perlakuan D memberikan hasil yang berpengaruh nyata pada parameter pengamatan seperti tinggi tanaman, jumlah daun, luas daun, dan berat basah tanaman.

\section{DAFTAR PUSTAKA}

Anggraini, S. D. (2017). Pola Pertumbuhan Tanaman Sawi Hijau (Brassica Juncea L) dengan Pemberian Slurry Biogas Kotoran Sapi Pada Hidroponik NFT. Malang: Universitas Brawijaya.

Asmana, M. S., Abdullah, S. H., \& Dwi Putra, G. M. (2017). Analisis Keseragaman Aspek Fertigasi Pada Desain Sistem Hidroponik Dengan Perlakuan Kemiringan Talang. Jurnal Ilmiah Rekayasa Pertanian dan Biosistem, 5(1), 303-315.
Buntoro, B. H., Rogomulyo, R., \& Trisnowati, S. (2014). Pengaruh Takaran Pupuk Kandang dan Intensitas Cahaya Terhadap Pertumbuhan dan Hasil Temu Putih (Curcuma zedoaria L.). Vegetalika, 3(4), 29 - 39.

Frasetya, B., Taofik, A., \& Firdaus, R. K. (2018). Evaluasi Variasi Nilai Electrical Conductivity (EC) Terhadap Pertumbuhan Tanaman Selada (Lactuca Sativa L.) Pada Sistem NFT. Jurnal Agro 5(2), 95102.

Hartus, T. (2010). Berkebun Hidroponik Secara Murah. Edisi IX. Jakarta: Penebar Swadaya.

Ifanto, I., \& Suprihati. (2019). . Pengaruh EC Saat Pembibitan Terhadap Hasil Sawi (Brassica rapa L.) Metode Hidroponik Sistem Apung . AGRITECH, 22(2), 118-128.

Pratiwi, P. R., Subandi, M., \& Mustari, E. (2015). Pengaruh Tingkat EC (Electrical Conductivity) Terhadap Pertumbuhan Tanaman Sawi (Rrassica Juncea L) Pada Sistem Instalasi Aeroponic Vertikal. Jurnal Agro, 2(1), 50-55.

Priyanggi, R. W., Nugroho, R. A., \& Sari, Y. P. (2019). Pengaruh Rasio Pupuk Organik Cair Limbah Ikan Nila (Orechromis nilocitus) dengan Pupuk Inorgaik Komersial Terhadap Pertumbuhan Sawi Pakcoy (Brassica Rapa L.) Secara Hidroponik Rakit Apung. Bioprospek, 14 (1), 11-22.

Rizal, S. (2017). Pengaruh Nutrisi yang diberikan Terhadap Pertumbuhan Tanaman Sawi Pakcoy (Brassica Juncea L.) yang Ditanam Secara Hidrroponik. Sainmatika, 14(1), 3844. 
Rukmana. (2002). Bertanam Sayuran Petsai Dan Sawi. Yogyakarta: Kanisius.

Santoso, A., \& Widyawati, N. (2020). Pengaruh Umur Bibit terhadap Pertumbuhan dan Hasil Pakcoy (Brassica rapa ssp. chinensis) pada Hidroponik NFT. Vegetalika, 9(3), 464-473.

Sarido, L., \& Junia. (2017). Uji Pertumbuhan dan Hasil Tanaman Pakcoy (Brassica Rapa L.) dengan Pemberian Pupuk Organik Cair Pada System Hidroponik. Jurnal AGRIFOR, 16(1), 65-74.

Sarif, P., Hadid, A., \& Wahyudi, I. (2015). Pertumbuhan dan Hasil Tanaman Sawi (Brassica Juncea L.) Akibat Pemberian Berbagai Dosis Pupuk Urea. e-J. Agrotekbis, 3 (5), 585-591.

Sukawati, I. (2010). Pengaruh Kepekatan Larutan Nutrisi Organik terhadap Pertumbuhan dan Hasil Baby Kailan (Brassica oleraceae var. albo-glabra) pada Berbagai Komposisi Media Tanam dengan Sistem Hidroponik Substrat. In Skripsi. Surakarta: Fakultas Pertanian Universitas Sebelas Maret SUrakarta.

Suseno, \& Widyawati, N. (2020). Pengaruh Nilai EC Berbagai Pupuk Cair Majemuk Terhadap Pertumbuhan Vegetatif Kangkung Darat Pada Soilless Culture. Agrosains : Jurnal Penelitian Agronomi, 22(1), 12-15.

Tripama, B., \& Yahya, M. R. (2018). Respon Konsentrasi Nutrisi Hidroponik Terhadap Tiga Jenis Tanaman Sawi (Brassica Juncea L.). Agritrop, 16 (2), 237 - 249.
Wibowo, S., \& Asriyanti, A. (2013). Aplikasi Hidroponik NFT pada Budidaya Pakcoy (Brassica rapa chinensis). Jurnal Penelitian Pertanian Terapan, 13(3), 159-167.

Wijayani, A., \& Widodo, W. (2005). Usaha Meningkatkan Beberapa Varietas Tomat dengan Sistem Budidaya Hidroponik. Agricultural Science, 12 (1), $77-83$.

Yama, D. I., \& Hendro, K. (2019). Pertumbuhan dan Kandungan Klorofil Pakcoy (Brassica Rapa L) Pada Beberapa Konsentrasi AB MIX dengan Sistem Wick. Jurnal Teknologi, 12(1), 21-30. 